\title{
PERFIL SOCIODEMOGRÁFICO Y DELICTIVO EN MALTRATADORES ENCARCELADOS EN GRAN CANARIA POR VIOLENCIA DE GÉNERO EN EL ENTORNO FAMILIAR
}

\author{
Laura M. ${ }^{a}$ Huertas Alonso \\ Universidad de Las Palmas de Gran Canaria \\ laura_mha@hotmail.com
}

\section{Resumen}

Trabajo cuyo objetivo es analizar las características sociodemográficas y delictivas de hombres condenados por violencia de género en el ámbito de la pareja. La muestra está formada por 154 hombres de entre 21 y 64 ańos internados en las prisiones de Gran Canaria (Canarias, España). Los resultados muestran un perfil sociodemográfico heterogéneo. El $87 \%$ es de nacionalidad espańola, el 78,6\% recibió educación religiosa católica y el 60,4\% manifiesta tener buena salud. El 55,8\% se encontraba desempleado antes de la entrada en prisión, el $50,6 \%$ tiene estudios básicos incompletos y la profesión del 42,9\% es trabajo manual no cualificado. Aunque presentaban diversidad en el tipo delictivo, el más común eran quebrantamientos de penas y medidas (37\%). El 19,5\% había cometido delitos de violencia de género con anterioridad y el $60,4 \%$ presentaba denuncias previas de su pareja o expareja.

PALABRAs CLAVE: agresores, violencia de género, delito, sociodemografía, prisión.

\section{SOCIODEMOGRAPHIC AND DELICTIVE PROFILE IN BATTERERS INPRISONED IN GRAN CANARIA FOR GENDER VIOLENCE IN THE FAMILY ENVIRONMENT}

\section{Abstract}

This study analyzes the sociodemographic and criminal characteristics of men convicted of crimes of gender violence in the area of couple relationships. The sample consists of 154 men aged between 21 to 64 and admitted to the prisons of Gran Canaria (Canary Islands, Spain). The results show a heterogeneous sociodemographic profile. $87 \%$ of the sample is of Spanish nationality, $78.6 \%$ received Catholic religious education and $60.4 \%$ said they were in good health. $55.8 \%$ were unemployed before entering prison, $50.6 \%$ have unfinished basic studies and the $42.9 \%$ profession is unskilled manual work. Although they presented diversity in the type of crime, the most common was the breaking of restraining orders (37\%). 19.5\% had criminal recidivism since they had previously committed crimes of gender violence and $60.4 \%$ had had at least one prior complaint from their partner or former partner.

KEYwORDs: batterers, gender violence, crime, demographic characteristics, prison. 


\section{INTRODUCCIÓN}

Dentro de las múltiples manifestaciones de la violencia de género, la que es ejercida por el hombre hacia la mujer en el contexto de pareja supone un tema de estudio creciente en las dos últimas décadas en España. Para ayudar a comprender cómo se origina y reproduce este grave problema social, que supone una amenaza importante a la salud de las víctimas y viola sus derechos humanos, desde el campo de la investigación social se ha puesto el foco de interés en el análisis de los factores que influyen en que la violencia en la pareja sea una realidad global que aún está lejos de resolverse, a tenor de los datos que se publican desde las distintas organizaciones e instituciones nacionales e internacionales. La Organización Mundial de la Salud (en adelante OMS) ya denunciaba desde el año 1996 que se trata de un problema de salud pública. Según Vives, «el impacto de esta lacra social en la salud de las víctimas puede llegar a representar la pérdida de hasta una quinta parte de sus años de vida» (243). La OMS en su informe de 2013 sobre las estimaciones mundiales y regionales de la violencia contra la mujer estima que aproximadamente el $30 \%$ de las mujeres a nivel mundial han sufrido violencia, ya sea física o sexual, alguna vez durante su vida a manos de sus parejas o exparejas y que el 38\% de los asesinatos de mujeres fueron cometidos en el contexto de una relación de pareja. A niveles europeos este tipo de violencia se presenta en proporciones similares, ya que atendiendo al informe de la Agencia de los Derechos Fundamentales de la Unión Europea (European Union Agency for Fundamental Rights 2014) se estima que aproximadamente el 34\% de las mujeres mayores de 15 años y residentes en la UE han sufrido algún tipo de violencia física por parte de su pareja o expareja en algún momento de su vida, produciéndose el $91 \%$ de las conductas violentas durante la relación de pareja.

En España, pese a tener una de las leyes más avanzadas del mundo ${ }^{1}$, y pionera en Europa, que tiene una visión integral del problema, ya que no solo ofrece un marco legal para intervenir y condenar este tipo de violencia, sino mecanismos de respuesta institucional, jurídica, social y sanitaria a las víctimas de la violencia en la pareja, la realidad social muestra que sigue siendo un problema actual y complejo. La macroencuesta de violencia contra la mujer del Ministerio de Sanidad, Servicios Sociales e Igualdad, realizada en el año 2015 sobre una muestra de 10171 mujeres mayores de 16 años, ofrece datos ligeramente inferiores en un marco comparativo europeo e internacional. Atendiendo al tipo de maltrato sufrido en la relación de pareja, en Espańa los datos oscilan entre el 8,1\% de mujeres que habrían sido víctima de violencia sexual por parte de su pareja o expareja, hasta el 25,4\% que habría sufrido violencia psicológica de control. En relación con las muertes producidas, desde que se inició la contabilización institucional en el año 2003 la cifra de mujeres muertas apenas se ha reducido (ver tabla 1) y el porcentaje de casos en los que

${ }^{1}$ Ley Orgánica 1/2004, de 28 de diciembre, de Medidas de Protección Integral Contra la Violencia de Género. BOE núm. 313, de 29 de diciembre de 2004. 
había denuncia previa sobre el agresor oscila entre un 20-30\% del total de fallecidas. En cuanto a las denuncias por delitos de violencia en el ámbito de la pareja, el Ministerio Fiscal español publica anualmente los datos a nivel nacional observándose un aumento significativo en el último año y destacando que las denuncias falsas solo comportan el $0,01 \%$.

\begin{tabular}{|c|c|c|c|c|}
\hline \multicolumn{5}{|c|}{$\begin{array}{l}\text { TABLA 1. EVOLUCIÓN ANUAL DE CIFRAS INSTITUCIONALES } \\
\text { SOBRE VIOLENCIA DE GÉNERO EN ESPAÑA }\end{array}$} \\
\hline AÑ̃ & $\begin{array}{l}\text { N. }{ }^{\circ} \text { TOTAL } \\
\text { DE FALLECIDAS }\end{array}$ & $\begin{array}{l}\text { DENUNCIA } \\
\text { PREVIA \% }\end{array}$ & $\begin{array}{l}\text { N. }{ }^{\circ} \text { TOTAL } \\
\text { DENUNCIAS }\end{array}$ & $\begin{array}{l}\text { DENUNCIAS } \\
\text { FALSAS } \%\end{array}$ \\
\hline 2003 & 71 & & & \\
\hline 2004 & 72 & & & \\
\hline 2005 & 57 & & & \\
\hline 2006 & 69 & 31,9 & & \\
\hline 2007 & 71 & 29,6 & & \\
\hline 2008 & 76 & 23,7 & & \\
\hline 2009 & 56 & 25 & 135540 & 0,0088 \\
\hline 2010 & 73 & 30,1 & 134105 & 0,0052 \\
\hline 2011 & 61 & 24,2 & 134002 & 0,0089 \\
\hline 2012 & 52 & 19,2 & 128543 & 0,014 \\
\hline 2013 & 54 & 20,4 & 124894 & 0,0112 \\
\hline 2014 & 55 & 30,9 & 126742 & 0,0134 \\
\hline 2015 & 60 & 21,7 & 129193 & 0,0077 \\
\hline 2016 & $49^{*}$ & 36,4 & 142893 & 0,01 \\
\hline 2017 & $51^{* *}$ & 23,5 & 166260 & 0,013 \\
\hline 2018 & $48^{* *}$ & 29,2 & 166961 & \\
\hline 2019 & $35^{* *}$ & 20 & $40319^{* * *}$ & \\
\hline
\end{tabular}

* Se encuentran actualmente dos casos en fase de investigación.

** Se encuentra actualmente un caso en fase de investigación.

*** Datos correspondientes al primer trimestre de 2019.

Fuente: Poder Judicial y Ministerio de Sanidad, Servicios Sociales e Igualdad.

Pese a que hace más de una década de la elaboración e implementación de la Ley Orgánica 1/2004, de Medidas de Protección Integral Contra la Violencia de Género (en adelante LO 1/2004), ésta no ha estado exenta de controversias e imprecisiones aún por resolver. Atendiendo al análisis en relación con el tipo de violencia de género que contempla, Martín (221) destaca que la norma está falta de una visión holística que contemple otros tipos de conductas violentas sufridas por las mujeres por el mero hecho de serlo, otros tipos de violencia de género que no se circunscriben únicamente a un entorno de pareja, como pueden ser la prostitución o la mutilación genital femenina. Así mismo, la autora también destaca las deficiencias en la ley, no solo por la ausencia de perspectiva de género en su contenido y 
redacción, sino también por la dificultad para detectar otras violencias que no tienen una evidencia clara en el plano físico o externo como es por ejemplo el caso de la violencia psicológica (222). Esa consideración de la violencia física como la única violencia de género se ve en cierta medida apoyada por las campańas publicitarias que obvian otros tipos de violencia, como la económica o la psicológica (FERNÁnDEZ 142). Así mismo, Peixoto y Mauricio (166) destacan la ineficiencia de la citada ley al circunscribir la protección y ayuda a las víctimas exclusivamente a la interposición de una denuncia, teniendo en consideración que menos del $30 \%$ de las mujeres muertas a manos de sus parejas o exparejas habían denunciado a su agresor. Finalmente, defienden la prevención y el uso de medidas sociales de educación y socialización frente al uso casi exclusivo del castigo a los maltratadores como única vía de erradicación de la violencia que se produce en el ámbito de la pareja (Регхото y Mauricio 169; Martín 221).

\section{MODELOS EXPLICATIVOS DEL MALTRATO A LA MUJER POR SU PAREJA}

La explicación de cómo y por qué se produce este tipo de violencia, realizada en las últimas décadas, se ha abordado desde diferentes perspectivas. Algunas aproximaciones teóricas iniciales centraban el análisis en el hombre maltratador, apoyándose en teorías psicológicas que entendían al agresor como personas con algún tipo de enfermedad mental que justificaría el uso de la violencia hacia su pareja; o en teorías psicosociales cuya argumentación se sustentaba en el uso de la violencia como respuesta al entorno social negativo donde se desenvuelve el individuo como puede ser el desempleo, los fracasos o la insatisfacción personal, entre otras (PeLEGRÍN y GARCÉS DE LOS FAYOS 357).

Con mucha frecuencia se ha intentado estudiar la violencia en las relaciones interpersonales, sean de pareja o intrafamiliares, sin tener en cuenta la perspectiva de género. En este tipo de estudios se analizan las diferencias en el uso de la violencia entre hombres y mujeres, encontrándose que son bastante inferiores las cifras de «mujeres maltratadoras o violentas» en comparación con los hombres. Se plantea que, mientras que ellos son más proclives al uso de la violencia física y sexual asociada al control y la dominación, las mujeres utilizan mayormente la violencia psicológica como respuesta a un comportamiento o acción inadmisible de otra persona. Así mismo, se observa que la violencia ejercida por los hombres sobre las mujeres provoca consecuencias mucho más graves para ellas, consecuencias que no se limitan a más lesiones físicas, sino que también pueden incluir problemas como depresión o alcoholismo y que se agravan a edades más avanzadas (FERnÁnDEZ-Romero et al. 167; Sebastián et al. 79).

Sin embargo, gran parte de la doctrina defiende el papel del género como elemento sine qua non para entender la violencia masculina en una relación de pareja. Se parte de las teorías feministas que sitúan como causa principal de esta violencia la asimetría de poder entre hombres y mujeres sustentada en una marcada dicotomía en el ejercicio de los roles de género, la masculinidad asociada a una vida excitante y 
la feminidad asociada al servicio a los demás (BARBERÁ y MAYOR 164), actuando los estereotipos de género como sustratos principales para que la violencia en la pareja se produzca, y todo ello forma el sistema social patriarcal (CANTERA y BLANCH 122). Desde esta perspectiva la violencia es la consecuencia de la asociación histórica del estereotipo femenino con un menor poder social en comparación con la autoridad de la que sí disponen los hombres, diferencias en el ejercicio del poder que se apoyan en las construcciones sociales y culturales que tienden a perpetuar las diferencias de género (De Miguel 234; Ferrer, Bosch, Ramis y Navarro 251; Peixoto y Mauricio 163; Lorente 3; Cantera y Blanch 126; Duarte, Gómez y Carrillo 10; Expósito 20; Alencar-Rodrigues y Cantera 119; Delgado, Sánchez y Fernández-Dávila 770; Ferrer y Bosch 517).

Es entendido, por tanto, el concepto del género como un sistema cultural aprendido socialmente, transmitido entre generaciones y basado en estereotipos acerca de la masculinidad y la feminidad (Colás y Villaciervos 37), los cuales relegan a la mujer a un espacio privado y carente de dominio, statu quo que aporta beneficios para los hombres tales como la sumisión y el control de la mujer, o la sensación de poder o dominio para ellos (Echeburúa, Fernández-Montalvo y De la Cuesta 21; Casique y Ferreira 952). Cuando esa desigual distribución de poder en una relación heterosexual es cuestionada por la mujer es cuando se produce el sustrato en el que la violencia de género en el ámbito de la pareja se puede manifestar, haciendo que la asimetría comporte un riesgo para éstas de sufrir violencia (Vives-Cases et al. 245; Arrigoni et al. 8). Para Peixoto y Mauricio «la violencia es ejercida por la amenaza ficticia que sienten los hombres hacia su masculinidad» (163), es por tanto una cuestión de naturaleza ideológica en la que la violencia comporta un recurso «que la sociedad y la cultura pone a disposición de los hombres para su uso en caso de necesidad" (Expósito 21), entendiendo esa "necesidad» como el mantenimiento de la desigualdad entre hombres y mujeres, en el papel de masculinidad y feminidad socialmente aprendidos. Algunos estudios como, por ejemplo, el llevado a cabo por Holtzworth-Munroe y Stuart han establecido que en las parejas donde el poder es repartido entre ambos miembros existe un menor riesgo de sufrir violencia (476).

Desde otros sectores de la doctrina se profundiza en las creencias sobre el género, afirmando que un rasgo común y característico de los maltratadores en el ámbito de la pareja es la presencia de actitudes sexistas y misóginas que generan y mantienen la violencia de género (Ferrer y Bosch 18). En este sentido, para Vives et al. «las desigualdades de género promovidas por una rígida división de roles, una masculinidad entendida en términos de agresividad y violencia y un sentimiento promovido culturalmente de propiedad hacia la mujer tienen una influencia clave en la violencia del compañero íntimo" (242).

Desde organismos internacionales como la OMS (2003) se ha propuesto un modelo explicativo holístico que entiende que ningún factor por sí solo puede explicar en su totalidad el uso de la violencia. Según esta institución se debe considerar un modelo explicativo de corte multidimensional o ecológico, donde se tenga en cuenta la interacción entre el individuo y el entorno que le rodea, aunando una visión micro y macro de la realidad y abordando todos y cada uno de los sistemas en 
los que se desenvuelve y desarrolla la persona: a nivel individual, relacional o microsistema, comunitario o exosistema y social o macrosistema (véase tabla 2).

\begin{tabular}{|c|c|c|}
\hline Sistema & $\begin{array}{l}\text { FACTORES EXPLICATIVOS } \\
\text { DEL INDIVIDUO }\end{array}$ & APLICACIÓN A LA VIOLENCIA DE GÉNERO \\
\hline Individual & Biológicos e historia personal & $\begin{array}{l}\text { Factores sociodemográficos } \\
\text { Consumo de alcohol /drogas } \\
\text { Antecedentes de violencia } \\
\text { Presencia de trastornos psíquicos } \\
\text { o de personalidad }\end{array}$ \\
\hline Microsistema & Relaciones interpersonales cercanas & $\begin{array}{l}\text { Asimetría de poder en la pareja } \\
\text { Presencia de conflictos conyugales }\end{array}$ \\
\hline Exosistema & $\begin{array}{l}\text { Contexto cercano o comunitario } \\
\text { en el que se desenvuelve }\end{array}$ & $\begin{array}{c}\text { Situación laboral } \\
\text { Entorno social } \\
\text { Presencia de leyes y } \\
\text { respuesta institucional } \\
\text { Medios de comunicación }\end{array}$ \\
\hline Macrosistema & Estructura social & Desigualdad de género \\
\hline
\end{tabular}

Fuente: elaboración propia a partir del Informe de la OMS (2003).

El modelo ecológico aplicado a la violencia de género en la pareja explica el maltrato como consecuencia de la interacción del individuo con el entorno (CASIQUE y FerReira 955). A nivel individual comprende la ausencia o presencia de determinadas características como trastornos de personalidad o psíquicos, consumo de sustancias, haber sufrido maltrato en la infancia o ser violento en general. A nivel relacional (microsistema) se explicaría mediante las diferencias de poder que podrían existir dentro de la dinámica de la pareja y la presencia de conflictos interpersonales. En tercer lugar, el nivel comunitario (exosistema) explicaría la violencia en relación con la visión social que se tiene sobre ella, la efectividad o no del marco legal, la respuesta de las instituciones tanto a víctimas como a agresores y el papel de los medios de comunicación que actúan como normalizadores de la violencia (AlENCAR-Rodrigues y Cantera 123). Finalmente, el sistema social (macrosistema), que tiene en cuenta los valores sociales y culturales apoyados en una histórica desigualdad de género.

Por las múltiples implicaciones que tiene, tanto individuales como sociales, la violencia de género en el ámbito de la pareja solo puede ser entendida dentro de un complejo sistema de relaciones, de mecanismos que distribuyen desigualmente el poder entre hombres y mujeres y de elementos sociales y estructurales que favorecen un entorno hostil permisivo en el que la mujer puede ser víctima de conductas violentas perpetradas por su pareja o expareja, desde amenazas, coacciones e insultos hasta las expresiones más graves como las lesiones, las agresiones sexuales e incluso los asesinatos. 


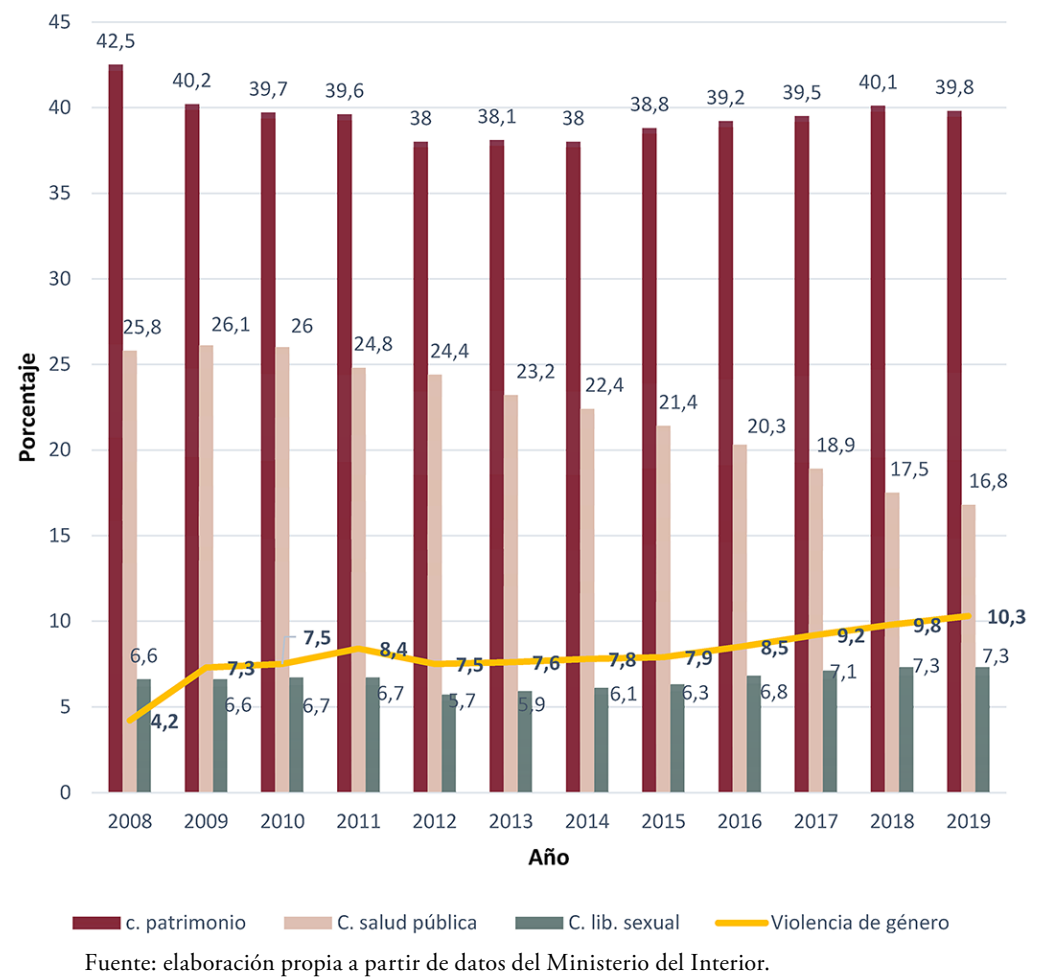

Gráfico 1. Evolución de hombres condenados según tipo delictivo LO 10/1995, del Código Penal, en las prisiones españolas (\%)

\section{SOCIODEMOGRAFÍA EN MALTRATADORES}

Como se ha venido exponiendo, la violencia de género en el ámbito de la pareja es un fenómeno complejo con múltiples imbricaciones y ello también se evidencia a la hora de estudiar las características sociodemográficas en los agresores. En la actualidad los hombres condenados por violencia de género suponen el tercer grupo más numeroso dentro de las cárceles españolas (4643 internos) tras los condenados por delitos contra el patrimonio (17 998) y contra la salud pública $(7601)^{2}$ (véase gráfico 1).

Pese a ser un colectivo notorio dentro de las prisiones espańolas y en constante aumento desde el ańo 2012, se advierte una carencia de trabajos sobre este grupo de población penitenciaria que tengan como objetivo principal el estudio de

2 Datos correspondientes a la estadística publicada por la Secretaría General de Instituciones Penitenciarias en el mes de mayo de 2019. 
las características sociodemográficas de los hombres agresores. En la actualidad no existen estudios sobre el colectivo de hombres internados en prisión por delitos de violencia de género que aporten datos a nivel nacional y que vayan más allá del estudio psicológico o la presencia de trastornos mentales de los condenados, lo cual sería de interés no solo en la búsqueda de factores comunes a tener en cuenta para futuras intervenciones y tratamientos con este colectivo, sino también para diseñar "políticas que vayan más allá de las soluciones de tipo judicial» (Borra 74).

En lo que aquí nos ocupa, las variables sociodemográficas en ocasiones se estudian de manera residual o complementaria a otras cuestiones como las características psicológicas y de personalidad, la intervención psicológica con agresores o los factores de riesgo (Fernández Montalvo, Echeburúa y Amor 160-161; Echeburúa, Fernández-Montalvo y De Corral 357-358; Echauri et al. 100-101; Arrigoni et al. 5-6; Boira y Jodrá 291-292; Subirana y Andrés 98-99; ChÉRREZ y AlÁs 11). Cuando la sociodemografía de los agresores es el objeto principal del estudio en la investigación en ocasiones se estudian utilizando fuentes indirectas como, por ejemplo, a través de la información de las víctimas (MATUD et al. 9-10) o a través de la consulta de bases de datos, como en el estudio realizado por Vives-Cases et al. (426) sobre el nivel socioeconómico de los hombres que maltratan a sus parejas, que se realizó a través de fuentes económicas de información indirectas internacionales. En otras ocasiones se utilizan otros datos como, por ejemplo, las denuncias policiales (Echeburúa, Fernández-Montalvo y Corral 358).

También se observa diversidad en el tipo de muestras estudiadas, no siendo infrecuente que se recurra a hombres condenados por delitos de violencia de género que se encuentran realizando un programa de tratamiento para agresores (FERnández-Montalvo y Echeburúa 155; Echeburúa, Fernández-Montalvo y Amor 3; Fernández-Montalvo, Echeburúa y Amor 160; Loinaz, Echeburúa y Torrubia 107; Boira y Tomás-Aragonés 49; Arrigoni et al. 4; De los GalaNeS Y Tabernero 14; Subirana y Andrés 98).

Otro aspecto cuestionable es que el tamańo de la muestra con la que se realiza el estudio es en ocasiones insuficiente, o se carece de grupo control con el que comparar los resultados obtenidos en las investigaciones y poder sacar conclusiones relevantes tras la comparación entre los diferentes tipos de muestras. Como ejemplos se pueden citar el estudio realizado por Echeburúa, Fernández-Montalvo y Amor (3), cuya muestra estaba formada por 54 hombres; o el trabajo de Loinaz, Echeburúa y Torrubia (107), con una muestra de 50 participantes, entre otros.

Algunos trabajos que se han llevado a cabo se centran en el estudio de los agresores que, si bien han sido condenados por cometer delitos de violencia de género contra sus parejas o exparejas, se les ha suspendido la pena de prisión por la asistencia a programas de tratamiento, conforme a lo establecido en el art. 80 y ss. del Código Penal ${ }^{3}$ (Boira, López y Tomás 141; Boira y Tomás-Aragonés 49; Fer-

${ }^{3}$ Ley Orgánica 10/1995, de 23 de noviembre, del Código Penal, BOE núm. 281, de 24 de noviembre de 1995 . 
nández-Montalvo et al. 442; Arrigoni et al. 4; Boira et al. 20; De los Galanes y Tabernero 14; Pérez, Giménez-Salinas y De Juan 107; Subirana y Andrés 98; Vargas, Lila y Catalá-Miñana 43; Sordi, 301). Ello hace que tras su lectura y análisis se deban tener en cuenta algunas consideraciones: en primer lugar, que se trata de delitos con penas menos graves ${ }^{4}$, cuya condena a pena privativa de libertad se encuentra por debajo de los dos ańos y, por tanto, es susceptible de ser sustituida por programas de intervención si se cumplen otros requisitos, como por ejemplo ser delincuente primario o haber satisfecho la responsabilidad civil ${ }^{5}$ (CERvelló 113-114). Ello supone que no se considere a los agresores que han cometido delitos castigados con penas graves que supongan preceptivamente la privación de libertad. Y, en segundo lugar, esa sustitución a la pena de prisión hace que algunos agresores acudan «obligados» a los programas de intervención ${ }^{6}$, condicionados por la entrada en prisión si no cumplen con la medida alternativa o sustitutoria, lo que influye en la efectividad de los tratamientos.

Por todas estas cuestiones, las variables sociodemográficas de los agresores suponen un elemento de estudio imprescindible en la medida en que ayudan a comprender la heterogeneidad del problema de la violencia de género en la pareja y la posible existencia de grupos de mayor riesgo de ejercer violencia.

Del análisis de los diferentes estudios que se han llevado a cabo en España se puede concluir que es difícil sacar conclusiones generales debido a la dificultad de comparación entre las muestras por el tamaño y el tipo de las mismas (penitenciarias, extrapenitenciarias, pacientes de tratamientos psicológicos, etc.). Además, se debe tener en cuenta que, incluso dentro de las prisiones, los internos pueden encontrarse condenados cumpliendo la pena privativa de libertad o en situación preventiva a la espera de que se celebre el juicio. Estos últimos se encontrarían ante una situación excepcional, en primer lugar, porque se debe respetar el derecho fundamental de presunción de inocencia ${ }^{7}, y$, en segundo lugar, porque estos internos no podrían llevar a cabo un programa de tratamiento penitenciario puesto que éste es exclusivo para los penados ${ }^{8}$. Todo ello dificulta el poder extraer conclusiones generalizables basadas en datos sociodemográficos que resulten útiles y aporten un conocimiento integral del problema más allá del campo de la psicología, cuestión que se une al déficit de información en relación con la población de estudio: los hombres que ejercen violencia hacia sus parejas o exparejas.

Pese a las reservas mencionadas, sí que se pueden extraer algunas cuestiones relevantes para el estudio de los hombres agresores en relación con las variables sociodemográficas contenidas en los trabajos analizados. En primer lugar, son

${ }^{4}$ Se consideran penas menos graves la prisión de tres meses hasta cinco años conforme al art. 33.3.a del Código Penal.

${ }^{5}$ Conforme al art. 80.2 del Código Penal.

${ }^{6}$ En España más de 2/3 de los hombres que acuden a programas para maltratadores lo hacen obligatoriamente a través de un mandato judicial (Geldschläger et al., 2010).

Art. 24.2 de la Constitución espańola de 1978.

8 Art. 59.1 de la Ley Orgánica 1/1979 General Penitenciaria. 
una población heterogénea en relación con la edad, la formación de la que disponen, o la profesión a la que se dedican, lo cual hace inviable establecer un único perfil de hombre agresor atendiendo a la sociodemografía. En algunos estudios, donde se utilizan muestras más grandes, la edad de los agresores oscila entre los 18-71 años (Echauri et al. 100) o entre los 18-74 ańos (Fernández-Montalvo et al. 444). y la media de edad de los participantes en algunos estudios se podría situar en torno a los 38-40 años (Subirana y André, 99; Caravaca et al. 94; Chérrez y Alás 12).

En segundo lugar, no se evidencia asociación de conductas violentas hacia la pareja con la pertenencia a sectores poblacionales marginales sin formación o que presenten bajos recursos económicos. En lo relativo al nivel económico del agresor, los estudios analizados muestran porcentajes de niveles medios de entre el $32 \%$ y el $40 \%$ de la muestra estudiada y niveles medio-altos de entre el 3\% y el 24\% (ECHEburúa, Fernández-Montalvo y Amor 8; Echeburúa, Fernández-Montalvo y Corral 360; Subinara y Andrés 99).

En tercer lugar, la procedencia de los hombres que cometen este tipo de delitos en Espańa es mayoritariamente la nacional oscilando entre el 50\% y el 90\% (CHÉrrez y Alás 12; Subinara y André, 99; Caravaca et al. 95; Cruz y Martín 3).

En cuarto lugar, se observa que, cuando la muestra se obtiene del interior de las prisiones. el grupo de divorciados es significativamente mayor (ECHEBURÚA, Fernández-Montalvo y Amor 6; Fernández-Montalvo y Echeburúa 195) en comparación con muestras estudiadas que pertenecen a grupos de tratamiento en la comunidad o extrapenitenciarios. Finalmente, en relación con la situación de desempleo, en algunos estudios se plantea que puede constituir un factor de riesgo para cometer delitos contra la pareja (ConTreras 689). De hecho, se ha encontrado que en algunos de los estudios analizados las tasas de desempleo eran significativamente altas oscilando entre el $38 \%$ y el $47 \%$ de la muestra estudiada (FERNÁndez-Montalvo et al. 445; Caravaca et al. 95; Arrigoni et al. 4).

Todo ello evidencia la necesidad de profundizar en el estudio de la sociodemografía como eje inicial para el conocimiento de las circunstancias personales y el contexto inmediato de los hombres agresores, tanto los que se encuentran condenados dentro de las prisiones españolas, participen o no en programas intra penitenciarios sobre violencia de género ${ }^{9}$, como a los que se les ha sustituido o suspendido la pena de prisión por programas de tratamiento en la comunidad.

El análisis de las variables sociodemográficas de estudios realizados en España con agresores hacia la pareja evidencia la dificultad de establecer perfiles de maltratadores por carecer de estudios empíricos a nivel nacional o bien por no disponer de muestras de estudio comparables y lo suficientemente amplias y represen-

${ }_{9}$ En el sistema penitenciario español se lleva a cabo el Programas de Intervención para Agresores (PRIA), que, si bien es obligatorio para los agresores a los que se les ha sustituido o suspendido la pena de prisión, dentro de las cárceles forma parte del tratamiento penitenciario, lo que supone que la participación en el mismo sea de carácter voluntario para los internos. 
tativas. Pese a ello, desde la psicología se han liderado diversas investigaciones cuyo objetivo es identificar tipologías o clasificaciones de agresores, si bien no existe unanimidad a la hora de categorizar a los maltratadores debido a las múltiples variables que se estudian (psicopatológicas, distorsiones cognitivas, tipo de violencia empleada, extensión de la violencia hacia otras personas o la actitud de la víctima, entre otras), y se han establecido diferentes categorías de hombres agresores que se resumen a continuación.

Pese a la diversidad, en la literatura científica acerca de las tipologías de agresores existen al menos tres clasificaciones ampliamente difundidas. En orden cronológico, la primera de ellas fue la realizada por Dutton (14-15), el cual hizó una distinción de tres tipologías de agresores:

1) Hipercontroladores, que suponen el $40 \%$ de los agresores y se caracterizan por elevados niveles de frustración y resentimiento que se traducen en la utilización de la violencia, la dominación y el aislamiento hacia su pareja.

2) Emocionalmente inestables, que suponen el $30 \%$ de los agresores, y mantienen relaciones cíclicas en la relación de pareja donde se suceden episodios de tensión, explosión y arrepentimiento.

3) Antisociales, que suponen el $30 \%$ de los agresores y utilizan la violencia como herramienta para resolver los conflictos.

Una segunda clasificación es la realizada por Holtzworth-Munroe y Stuart (481-482). Estos autores clasifican a los hombres agresores de pareja basándose en tres aspectos: la psicopatología del maltratador, contra quién ejercen las conductas violentas y el tipo de violencia que perpetran, y distinguen tres tipos de agresores:

1) Maltratadores solo en la familia, que se caracterizan por menor presencia de psicopatología, menor severidad en las conductas violentas y presentar estrés o ira, pero mantienen una actitud positiva hacia las mujeres.

2) Maltratadores «disfóricos» 0 «borderline», que se caracterizan por ejercer violencia de tipo grave solo a la pareja, con presencia de abuso de alcohol y/o drogas, presentar dificultades para controlar la ira, y se muestran dependientes y celosos.

3) Maltratadores generalmente violentos o antisociales, los cuales presentan un historial extenso de comportamientos violentos, con abuso de alcohol y/o drogas y siendo más propensos a presentar trastornos de personalidad antisociales. Además, conciben la violencia como una herramienta aceptable y la utilización de la misma hacia su pareja es una extensión más de su uso, presentando con mayor frecuencia exposiciones a la violencia en su familia de origen.

Por su parte, Gottman et al. (235) clasificaron a los agresores en dos grandes grupos:

1) Maltratadores «cobra» o tipo 1, que son hombres con un elevado uso de la violencia, antisociales y con alta probabilidad de presentar adicciones. 
2) Maltratadores "pitbull» o tipo 2, que se caracterizan por presentar elevada ira, utilización impulsiva de la violencia, presencia de trastornos de tipo borderline y dificultad para expresar las emociones.

En España también se han llevado a cabo estudios cuyo objetivo es establecer nuevas tipologías de agresores en el ámbito de la pareja o comparar los resultados de sus estudios con las clasificaciones tradicionales. En el trabajo realizado por Fernández-Montalvo y Echeburúa (171) se distinguen cuatro tipos de maltratadores tras analizar dos elementos: la extensión de la violencia que ejercen los agresores y el perfil psicopatológico de los mismos en una muestra de 42 participantes. Estos autores aportaron la siguiente clasificación:

Según la extensión de la violencia:

1) Violento solo en el hogar: tipología compuesta por el $74 \%$ de la muestra estudiada y la conforman hombres que ejercen maltrato grave en el hogar, pero socialmente mantienen conductas adecuadas.

2) Violento en general: suponen el $26 \%$ de la muestra, son personas violentas en general y con mayor frecuencia de haber sufrido maltrato en la infancia. Muestran distorsiones cognitivas en relación con el uso de la violencia como forma de resolver los conflictos.

Según el perfil psicopatológico:

1) Sin habilidades interpersonales, grupo que conformaba el 55\% de la muestra y presentaba carencias de habilidades sociales y la utilización de la violencia porque no tenían otros mecanismos de solución de conflictos.

2) Sin control de los impulsos, que suponían el $45 \%$ de los participantes y se caracterizaban por la presencia de episodios bruscos e inesperados de descontrol de la ira e incapacidad para controlar la violencia que ejercen.

Por su parte, Loinaz, Echeburúa y Torrubia (110) establecieron dos tipos diferenciados de agresores:

1) Violentos con la parejalestables emocionalmente/integrados socialmente, los cuales ejercen violencia limitada al ámbito de la pareja, muestran menor abuso de sustancias y menor presencia de distorsiones cognitivas.

2) Violentos generalizados/poco estables emocionalmente/integrados socialmente, que ejercen violencia más allá del ámbito familiar, con mayor presencia de abuso de alcohol y/o drogas, alteraciones de la personalidad y mayor presencia de distorsiones cognitivas.

Finalmente, Castellano et al. (23-25) establecieron cinco perfiles de hombres agresores tras una valoración psicológico-psiquiátrica distinguiendo los siguientes: 
1) Hombre cuyo perfil encaja en el eje del neuroticismo: presenta características como ser joven, emocionalmente introvertido, inseguro y dependiente con un alto nivel de ansiedad.

2) Maltratador fásico: hombres con inestabilidad emocional, extrovertidos, con tendencia a la ansiedad y estado de ánimo inestable.

3) Maltratador psicótico: presentan baja afectividad, alejamiento emocional, dureza de carácter, alta autoestima e independencia y una elevada preocupación por su imagen social.

4) Maltratador de denuncia tardía: hombres cuya edad supera los 55-60 ańos y presentan un comportamiento tradicional-patriarcal. La actitud reivindicativa de la pareja provoca que el agresor reaccione con dominación, orgullo y agresividad.

5) Maltratador que abusa de alcohol/drogas, donde se distinguen tres subtipos de agresores: el «bebedor cultural» (llega a casa bebido, lo que puede derivar en una agresión física), «bebedor excesivo» (las agresiones son más frecuentes y a edades avanzadas puede suponer un bajo control de los instintos y conductas de tipo explosivas) y el subtipo de "consumidor de drogas» (presentan impulsividad y la generación de un estado de primitivismo).

Tal diversidad evidencia la relevancia de seguir estudiando las características de los hombres que maltratan a su pareja con la finalidad última de diseñar políticas sociales que sean eficaces para la erradicación de la lacra social del maltrato a la mujer por su pareja. Por tanto, el objetivo del presente trabajo es analizar el perfil sociodemográfico y delictivo de los maltratadores encarcelados en Gran Canaria por violencia de género en el entorno familiar. Además, también se analizarán sus creencias religiosas, estado de salud y consumo de sustancias.

\section{INVESTIGACIÓN EMPÍRICA}

Con la finalidad de conocer las características sociodemográficas y delictivas de los hombres que han sido condenados por violencia de género hacia su pareja se diseńó una entrevista que ha sido aplicada a un total de 154 hombres que durante los años 2015 y 2016 cumplían condena en los centros penitenciarios Salto del Negro y Las Palmas II de la provincia de Las Palmas. El acceso a la muestra fue a través de un listado de hombres condenados por delitos de violencia de género facilitado por cada centro penitenciario y se recogieron los datos de aquellos internos que, previa explicación de los objetivos y la metodología del estudio, prestaron su consentimiento informado y quisieron colaborar voluntariamente. Las entrevistas fueron realizadas por una trabajadora social formada en violencia de género y los datos fueron recogidos de manera anonimizada para garantizar la confidencialidad de los participantes.

Los criterios de selección de la muestra son estar condenado por algún delito de violencia de género, encontrarse cumpliendo condena por ese mismo delito en el momento de la entrevista y no presentar enfermedad mental grave o cualquier otra patología que impida o dificulte la comprensión. 
En la tabla 3 se muestra el delito de violencia de género por el que estaban en prisión los hombres de la muestra de estudio. Como puede observarse, aunque se da mucha diversidad, lo más frecuente es que estuviesen en prisión por quebrantamiento de la orden de alejamiento, lo cual se daba en más de la tercera parte de la muestra. El segundo tipo de delito más frecuente fue el de malos tratos, que se daba en poco más de la cuarta parte. Aunque era menos frecuente, varios de los hombres estaban en prisión por amenazas o por lesiones a su pareja o expareja, y lo menos frecuente es que estuviesen en prisión por maltrato psicológico o por allanamiento de morada. Destaca que varios de ellos estaban en prisión por asesinato de la mujer o por intento de asesinato.

\begin{tabular}{ccc}
\hline \multicolumn{3}{c}{ TABLA 3. DELITO DE VIOLENCIA DE GÉNERO POR EL QUE ESTABAN } \\
EN PRISIÓN LOS HOMBRES DE LA MUESTRA DE ESTUDIO \\
\hline Tipo DE DELITO DE violENCIA DE GÉNERO & $\mathrm{N}$ & $\%$ \\
\hline Malos tratos & 41 & 26,6 \\
\hline Quebrantamiento de orden de alejamiento & 57 & 37,0 \\
\hline Agresion sexual & 4 & 2,6 \\
\hline Amenazas & 21 & 13,6 \\
\hline Lesiones & 18 & 11,7 \\
\hline Homicidio/asesinato & 6 & 3,9 \\
\hline Maltrato psicológico & 1 &, 6 \\
\hline Coacciones & 2 & 1,3 \\
\hline Tentativa de homicidio/asesinato & 3 & 1,9 \\
\hline Allanamiento de morada & 1 & 100,0 \\
\hline Total & 154 & \\
\hline
\end{tabular}

\subsection{Características SOCIOdEMOgRÁficas, CREenCias RELigiosas, estado de SALUD Y CONSUMO DE SUSTANCIAS}

$\mathrm{Al}$ analizar sus características sociodemográficas se encontró mucha diversidad en su edad, que oscilaba entre 21 y 64 años (véase gráfico 2), siendo la media 40,31, la desviación típica 10,66 y la mediana 40.

En la tabla 4 se muestra su estado civil. Como puede observarse, se da gran diversidad, si bien casi la mitad (el 40,9\%) estaba soltero. Prácticamente la tercera parte de los participantes estaba casado o tenía pareja de hecho, casi la cuarta parte se había separado o divorciado, y tres de ellos habían enviudado. Al preguntarles por el número de parejas que tenían o habían tenido también se encontró diversidad, oscilando entre una, lo que se daba en el 17,5\% de los hombres, y 10, de lo que informaron dos hombres. Lo más frecuente es que hubieran tenido dos, de lo que informó el 34,4\%, o tres (el 22,7\%), pero bastantes hombres informaron de haber tenido cuatro parejas (el 9,7\%), cinco (el 7,1\%) o seis (el 4,5\%). El 18,8\% afirmó que su pareja actual era la víctima. 


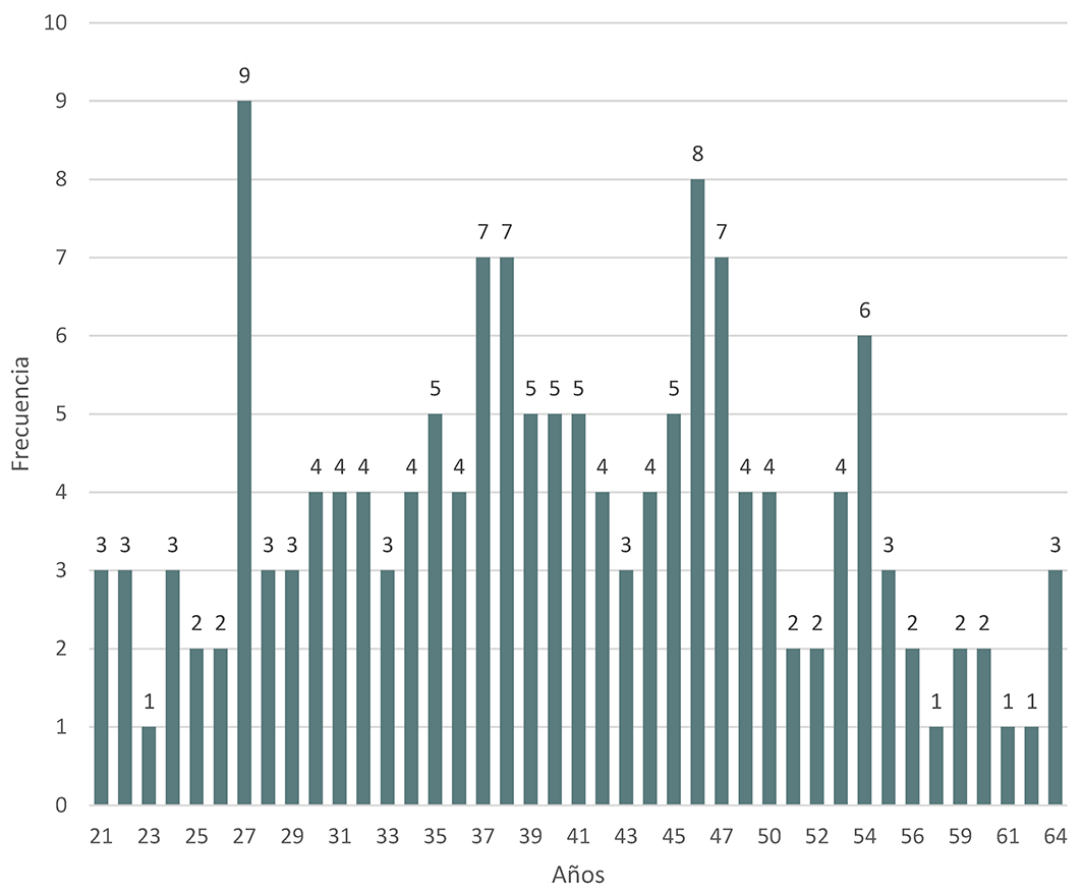

Gráfico 2. Edad de la muestra de estudio.

\begin{tabular}{ccc}
\hline TABLA 4. ESTADO CIVIL DE LA MUESTRA DE ESTUDIO & \\
\hline & $\mathrm{N}$ & $\%$ \\
\hline Soltero & 63 & 40,9 \\
\hline Casado & 18 & 11,7 \\
\hline Pareja de hecho & 34 & 22,1 \\
\hline Separado, divorciado & 33 & 21,4 \\
\hline Viudo & 3 & 1,9 \\
\hline Trámites de separación & 3 & 1,9 \\
\hline Total & 154 & 100,0 \\
\hline
\end{tabular}

Poco más de la cuarta parte de los maltratadores (el 28,6\%) no tenía hijos/as y el resto tenía entre uno/a y nueve, lo que únicamente se daba en un caso, siendo lo más frecuente que tuviesen uno/a (el 26\%), dos (el 21,4\%) o tres hijos/as (el 13,6\%). La media del número de hijos/as era 1,62, la desviación típica 1,60 y la mediana 1 . También había mucha diversidad en las edades de sus hijos/as, oscilando entre menos de un año y 42 años.

También se daba diversidad en su nivel de estudios, tal y como puede observarse en la tabla 5, si bien la mitad no había finalizado los estudios básicos. Ade- 
más, prácticamente la cuarta parte únicamente había finalizado los estudios básicos. Pero, aunque eran minoría, también había hombres que habían cursado estudios universitarios.

\begin{tabular}{ccc}
\hline \multicolumn{2}{c}{ TABLA 5. NIVEL DE ESTUDIOS DE LA MUESTRA DE ESTUDIO } \\
\hline & $\mathrm{N}$ & $\%$ \\
\hline Analfabeto & 6 & 3,9 \\
\hline Básicos sin terminar & 78 & 50,6 \\
\hline Básicos terminados & 36 & 23,4 \\
\hline FP I, módulos básicos & 12 & 7,8 \\
\hline BUP/COU/Bachiller & 12 & 7,8 \\
\hline Técnico sup., FP II, & 3 & 1,9 \\
\hline Grado universitario, diplomatura, primer ciclo & 5 & 3,2 \\
\hline Licenciado, $2 .^{\circ}$ ciclo, máster & 2 & 1,3 \\
\hline Total & 154 & 100,0 \\
\hline
\end{tabular}

En la tabla 6 se muestran los datos relativos a la profesión de los hombres que conforman la muestra de estudio. Como puede observarse, aunque se da diversidad, casi la mitad (el 42,9\%) tenía trabajos de tipo manual no cualificados tales como, por ejemplo, peón de la construcción, de jardinería, repartidor o mozo de almacén. Poco más de la tercera parte tenía trabajos de tipo manual cualificado tales como, por ejemplo, mecánico, encofrador, tornero, fontanero, marinero, pastelero, gruista o cocinero. El 14,3\% tenía trabajo de tipo no manual tales como, por ejemplo, militar sin graduación, administrativo o vigilante de seguridad. Uno de ellos era diplomado universitario, otro estudiante y tres eran autónomos, ejerciendo profesiones tan diversas como cantante, tatuador o luchador profesional. Además, dos eran hombres jóvenes que no tenían profesión y afirmaron que eran pensionistas.

\begin{tabular}{ccc}
\hline \multicolumn{2}{c}{ TABLA 6. PROFESIÓN DE LA MUESTRA DE ESTUDIO } & \\
\hline & $\mathrm{N}$ & $\%$ \\
\hline Estudiante & 1 &, 6 \\
\hline Trabajo manual no cualificado & 66 & 42,9 \\
\hline Trabajo manual cualificado & 59 & 38,3 \\
\hline Trabajo no manual & 22 & 14,3 \\
\hline Diplomados & 1 &, 6 \\
\hline Pensionistas & 2 & 1,3 \\
\hline Autónomos & 3 & 1,9 \\
\hline Total & 154 & 100,0 \\
\hline
\end{tabular}

En la tabla 7 se muestra la actividad laboral antes de entrar en prisión. Como puede observarse, poco más de la mitad estaba en situación de desempleo y úni- 
camente poco más de la tercera parte estaba en activo. También destaca que cinco eran pensionistas, dos se habían jubilado y uno estaba de excedencia.

\begin{tabular}{ccc}
\hline \multicolumn{2}{c}{ TABLA 7. ACTIVIDAD LABORAL ANTES DE ENTRAR EN PRISIÓN } \\
DE LA MUESTRA DE ESTUDIO
\end{tabular}

Aunque la mayoría (el 87\%) eran españoles, también se observó gran diversidad en la nacionalidad de los maltratadores en prisión que conforman la muestra de estudio, tal y como se muestra en la tabla 8, con hombres procedentes tanto de Europa como de África y de América.

\begin{tabular}{ccc}
\hline TABLA 8. NACIONALIDAD DE LOS HOMBRES DE LA MUESTRA DE ESTUDIO \\
\hline & $\mathrm{N}$ & $\%$ \\
\hline Espańola & 134 & 87,0 \\
\hline Francesa & 1 &, 6 \\
\hline Italiana & 3 & 1,9 \\
\hline Senegalesa & 2 & 1,3 \\
\hline Holandesa & 2 & 1,3 \\
\hline Marroquí & 4 & 2,6 \\
\hline Colombiana & 1 &, 6 \\
\hline Venezolana & 2 & 1,3 \\
\hline Argelina & 1 &, 6 \\
\hline Argentina & 2 & 1,3 \\
\hline Chilena & 1 &, 6 \\
\hline Polaca & 1 &, 6 \\
\hline Total & 154 & 100,0 \\
\hline & & \\
\hline
\end{tabular}

En la tabla 9 se muestra la información relativa a la educación religiosa. Destaca que eran minoría los hombres maltratadores en prisión que no habían recibido educación religiosa. $Y$, aunque se daba bastante diversidad, lo más frecuente es que hubiesen sido educados en la religión católica. Al preguntarles por el grado de prác- 
tica el 38,3\% informó que era poco practicante, uno dijo que practicaba mucho y el resto (el 61\%) no tenía práctica religiosa. Pese a ello, solo poco más de la tercera parte (el 39\%) dijo que la religión no era importante para él; para el 20,1\% la religión era poco importante, medianamente importante para el 3,9\%, muy importante para el 5,2\% e importante para el 31,8\%.

\begin{tabular}{ccc}
\hline TABLA 9. EDUCACIÓN RELIGIOSA DE LOS HOMBRES DE LA MUESTRA DE ESTUDIO \\
\hline & $\mathrm{N}$ & $\%$ \\
\hline Sin educación religiosa & 23 & 14,9 \\
\hline Católica & 121 & 78,6 \\
\hline Evangelica & 3 & 1,9 \\
\hline Musulmana & 4 & 2,6 \\
\hline Otra cristiana & 2 & 1,3 \\
\hline Yoruba/santería & 1 &, 6 \\
\hline Total & 154 & 100,0 \\
\hline
\end{tabular}

Los datos relativos a su estado de salud autoinformada se muestran en la tabla 10. Como puede observarse, más de la mitad de maltratadores en prisión valoraban su salud como buena y casi la quinta parte la consideraba «muy buena». Solo uno dijo que su salud era muy mala, el $13,6 \%$ dijo tener mala salud y el resto afirmó tener una salud aceptable. El 39\% de los maltratadores dijo tener tratamiento médico, destacando que el $32,5 \%$ informó de estar tomando ansiolíticos y el $18,2 \%$ antidepresivos.

\begin{tabular}{ccc}
\hline \multicolumn{2}{c}{ TABLA 10. SALUD AUTOINFORMADA DE LOS HOMBRES } \\
DE LA MUESTRA DE ESTUDIO \\
\hline \\
Muy mala & $\mathrm{N}$ & $\%$ \\
\hline Mala & 21 &, 6 \\
\hline Aceptable & 10 & 13,6 \\
\hline Buena & 93 & 6,5 \\
\hline Muy buena & 29 & 60,4 \\
\hline Total & 154 & 18,8 \\
\hline
\end{tabular}

El 26\% de los maltratadores dijo que no fumaba tabaco, existiendo bastante diversidad en el resto en el número de cigarrillos que fumaba al día, que oscilaba entre 2 y 60 , siendo la media 10,90, la desviación típica 11,61 y la mediana 10. Al preguntarles si tomaban bebidas alcohólicas antes de entrar a prisión el 65,6\% dijo que no y el $34,4 \%$ dijo que sí. Se encontró mucha diversidad en el tipo de bebidas que tomaban, aunque lo más común era vino, cerveza, coñac, ron, ginebra y whisky, siendo lo más frecuente que tomasen más de un tipo de bebida. También había mucha diversidad en la cantidad de copas consumidas semanalmente, que 
oscilaba desde tres hasta 84 , si bien la mayoría de los que bebían tomaban entre 10 y 28 copas a la semana.

En la tabla 11 se muestran los datos relativos al consumo de drogas. Como puede observarse, más de la mitad de los maltratadores en prisión informaron de consumir drogas. Aunque lo más frecuente era el hachís, lo que se daba en casi la cuarta parte de los maltratadores, y casi la décima parte consumía cocaína, había mucha diversidad en el consumo, tal y como puede observarse en la tabla 11. Además, también se daba gran diversidad en la cantidad de droga que consumían.

\begin{tabular}{ccc}
\hline TABLA 11. CONSUMO DE DROGAS DE LOS HOMBRES DE LA MUESTRA DE ESTUDIO \\
\hline & N & $\%$ \\
\hline No consume & 73 & 47,4 \\
\hline Hachís & 33 & 21,4 \\
\hline Cocaína & 15 & 9,7 \\
\hline Trankimazin & 2 & 1,3 \\
\hline Heroína, cocaína & 4 & 2,6 \\
\hline Hachís y cocaína & 5 & 3,2 \\
\hline Heroína & 6 & 3,9 \\
\hline Hachís, crack y cocaína & 2 & 1,3 \\
\hline Heroína y hachís & 3 & 1,9 \\
\hline Anfetaminas y hachís & 1 &, 6 \\
\hline Heroína, cocaína y hachís & 3 & 1,9 \\
\hline Heroína y crack & 1 &, 6 \\
\hline Hachís y benzodiacepinas & 2 & 1,3 \\
\hline Cocaína, crack y barbitúricos & 1 &, 6 \\
\hline Cocaína, heroína, hachís, crack, pastillas & 1 &, 6 \\
\hline Cocaína, anfetaminas, hachís y éxtasis & 1 &, 6 \\
\hline Cocaína y anfetaminas & 1 &, 6 \\
\hline Total & 154 & 100,0 \\
\hline
\end{tabular}

\subsection{Características Penales}

Como ya se ha citado, se daba gran diversidad en el tipo de delito de violencia de género por el que se encontraban en prisión. También había diversidad en el tiempo que llevaban en prisión, oscilando desde un mes hasta 16 ańos, siendo la media 23,34 meses, la desviación típica 32,87 meses y la mediana nueve meses. Para poco menos de la mitad de maltratadores (el $42,9 \%$ ) ésta era la única vez que había estado en prisión, pero el resto lo había estado entre una y 19 ocasiones más, circunstancia esta última de la que únicamente informó uno de los hombres. Lo más frecuente era que hubiesen estado una vez anteriormente (el 25,3\%), o dos (el 12,3\%). 
El número total de delitos imputados oscilaba entre uno y 17, siendo la medida 3,68, la deviación típica de 2,99 y la mediana de 3. Se daba gran diversidad en los tipos de delitos que no eran violencia de género cometidos e incluían robos/ hurtos, delitos contra la salud pública, asesinato/homicidio, quebrantamiento de condena, lesiones, delitos contra la seguridad del tráfico, atentado a la autoridad, falsificación de documento público, amenazas, obstrucción a la justicia, conducción temeraria, encubrimiento y estafa, entre otros. También se daba diversidad en el número de delitos de violencia de género cometidos, oscilando entre uno y siete, cifra que se daba en dos casos. La media era de 1,88, la desviación típica de 1,07 y la mediana de 2 . Aunque casi la mitad (el 42,2\%) solo había cometido un delito de violencia de género, más de la tercera parte (el 39,6\%) habían cometido dos, tres delitos el $11 \%$ de los maltratadores y cuatro el $4,5 \%$. Entre los delitos de violencia de género cometidos se encontraban los malos tratos, quebrantamiento de orden de alejamiento, agresión sexual, amenazas, lesiones, maltrato psicológico, coacciones, daños contra la integridad moral, daños en las cosas, homicidio/asesinato consumado o en grado de tentativa y allanamiento de morada, entre otros.

El 19,5\% de maltratadores había cometido anteriormente delitos de violencia de género, el $27,9 \%$ había cometido anteriormente delitos que no eran violencia de género y el 20,8\% había cometido anteriormente tanto delitos de violencia de género como delitos que no eran violencia de género.

En la tabla 12 se muestran los datos relativos a si tenía orden de alejamiento. Como puede observarse solo el 12,3\% no tenía tal orden. Aunque lo más frecuente es que se tratase del alejamiento de la expareja, en algunos casos era de la pareja actual y en tres casos de la amante.

\begin{tabular}{ccc}
\hline TABLA 12. ORDEN DE ALEJAMIENTO DE LOS HOMBRES DE LA MUESTRA DE ESTUDIO \\
\hline & $\mathrm{N}$ & $\%$ \\
\hline No tenía orden de alejamiento & 19 & 12,3 \\
\hline De la pareja actual & 25 & 16,2 \\
\hline De la ex pareja/víctima & 107 & 69,5 \\
\hline De la amante & 3 & 1,9 \\
\hline Total & 154 & 100,0 \\
\hline
\end{tabular}

Al preguntar a los maltratadores si habían sido denunciados previamente por su pareja o expareja, 93 de los maltratadores (el 60,4\%) dijo haber sido denunciado al menos una vez. En la tabla 13 se muestran los datos relativos a tal denuncia. Como puede observarse, poco más de la tercera parte no tenía denuncias previas. Aunque se da una cierta diversidad en las causas de tal denuncia, lo más frecuente era por maltrato físico, lo que se dio en poco más de la cuarta parte de los casos. El $11 \%$ de los maltratadores en prisión informó de haber sido denunciado en más de una ocasión, siendo lo más frecuente por amenazas (el 6,5\%), por maltrato físico (el $3,2 \%)$, por quebrantamiento de la orden de alejamiento en un caso y por maltrato psicológico en el otro. 


\begin{tabular}{ccc}
\hline $\begin{array}{c}\text { TABLA 13. DENUNCIA PREVIA DE LA PAREJA O EXPAREJA } \\
\text { DE LOS HOMBRES DE LA MUESTRA DE ESTUDIO }\end{array}$ \\
\hline N & $\%$ \\
\hline No tenía denuncia previa & 61 & 39,6 \\
\hline Por maltrato psicológico & 25 & 16,2 \\
\hline Por maltrato físico & 42 & 27,3 \\
\hline Por amenazas & 22 & 14,3 \\
\hline Por quebrantamiento orden de alejamiento & 1 &, 6 \\
\hline Por coacciones & 3 & 1,9 \\
\hline Total & 154 & 100,0 \\
\hline
\end{tabular}

\section{CONCLUSIONES Y REFLEXIONES FINALES}

Los resultados del presente trabajo evidencian la diversidad sociodemográfica y penal de los hombres que cumplen condena en las cárceles de Gran Canaria por delitos de violencia de género.

La edad media encontrada en el presente estudio ( 40 ańos) coincide con la de otros que se han llevado a cabo en España dentro de las prisiones, tales como los estudios de Chérrez y Alás (32) o Caravaca et al. (94). La mayoría (el 87\%) de los agresores tienen nacionalidad española coincidiendo con otros estudios realizados en España como, por ejemplo, el de Loinaz, Echeburúa y Torrubia (108), donde se encontró que el $84 \%$ de los agresores eran de procedencia española, porcentaje que era del $82,6 \%$ en el estudio de Caravaca et al. (95) y del $87,9 \%$ en el de Cruz y Martín (3). Los extranjeros suponían el 13\% de la muestra estudiada y su procedencia es diversa, siendo originarios de países como Senegal, Holanda, Marruecos, Chile, Polonia o Italia, entre otras naciones.

El análisis del estado civil también muestra diversidad, aunque era más frecuente que fuesen solteros (40,9\%). También era diverso el historial de relaciones de pareja, aunque la mayoría $(79,7 \%)$ había mantenido relaciones estables con tres mujeres o menos a lo largo de su vida. Entre los resultados encontrados destaca que el $18,8 \%$ de la muestra afirmó que, aun estando en prisión cumpliendo condena por delitos de violencia de género, seguían manteniendo una relación sentimental con la víctima llegando a mantener contacto con ella el 6,4\%, principalmente a través del correo postal. Ello evidencia una situación delicada en la medida en que el mantenimiento de las relaciones de pareja donde ha existido un historial previo de maltrato, o la consumación de un delito de violencia de género, puede conllevar una situación de peligro para la víctima una vez que el agresor ha cumplido la condena de prisión y regresa al contexto donde se produjo el mismo; además, supone el quebrantamiento de las órdenes de alejamiento que impiden cualquier tipo de contacto o comunicación con la víctima del delito.

En el aspecto educativo y laboral la muestra también presenta variabilidad, si bien es mayoritario el grupo de hombres que tienen estudios básicos sin finalizar 
$(50,6 \%)$ o finalizados (23,4\%); aunque su profesión también era diversa, en el 42,9\% era de tipo manual no cualificado, encontrándose en situación de desempleo antes de la entrada en prisión el 55,8\% de los participantes. Aunque era mucho menos frecuente, en la muestra de estudio también había hombres con niveles de estudios superiores ( $4,5 \%$ de nivel universitario) y el $12,9 \%$ tenía estudios secundarios. La mayoría de los hombres habían recibido educación religiosa $(85,1 \%)$, siendo mayoritariamente la religión católica $(78,6 \%)$ la que profesaban los participantes, aunque el $61 \%$ de ellos informó que no eran practicantes de dicha religión.

$\mathrm{Al}$ analizar su estado de salud se encontró que el $60,4 \%$ de la muestra la calificaba como buena. El consumo de tabaco es muy frecuente en los participantes (74\%) y el consumo de alcohol era inferior, ya que solo 34,4\% afirmó consumir bebidas alcohólicas en la etapa anterior a la entrada en prisión, siendo muy variables las cantidades semanales consumidas, que oscilan entre las 10 y las 28 copas. Era más frecuente el consumo de estupefacientes, ya que el 52,6\% de los hombres informó que era consumidor de drogas, presentándose gran diversidad tanto en el tipo de drogas como en la cantidad semanal consumida, si bien la más consumida era el hachís, ya sea como sustancia única o junto a otro tipo de drogas como la cocaína o la heroína, entre otras.

En síntesis, el estudio de las características sociodemográficas en los agresores de violencia de género en la pareja no permite establecer un perfil de maltratador, aunque sí confirma la idea ampliamente extendida en la doctrina científica acerca de la variabilidad y la heterogeneidad que presentan los agresores. Sin embargo, sí que se encuentran similitudes con otros estudios en algunas variables estudiadas como por ejemplo la media de edad, la nacionalidad mayoritaria de españoles, los niveles educativos o la ocupación de los agresores (LoInaz, Echeburúa y Torrubia 108 y ss.; Caravaca et al. 95; Cruz y Martín 3), por lo que en determinadas características sociodemográficas sí se encuentran patrones similares en las muestras recogidas dentro de las prisiones españolas.

Al analizar las características penales también se encontró diversidad en el tipo de delito y en el historial delictivo de los agresores. En este sentido destaca que menos de la mitad de la muestra (42,9\%) eran delincuentes primarios, siendo lo más habitual que hayan entrado en prisión para cumplir una condena en más de una ocasión, dos veces para el $28 \%$ de la muestra y tres veces para el $11,6 \%$ de los participantes. Sin embargo, destaca que el $14,8 \%$ de la muestra está conformada por hombres multirreincidentes desde el punto de vista penal-penitenciario llegando a sumar más de cuatro condenas de prisión en su historial. En relación con el tipo de delito cometido, el 42,2\% solo contaba con un delito de violencia de género en su condena; sin embargo, más de la mitad acumulaban varios delitos de violencia de género, siendo lo más habitual dos delitos (39,6\%). Entre los delitos cometidos los más habituales son el quebrantamiento de orden de alejamiento (37\%), los malos tratos $(26,6 \%)$ y las amenazas $(13,6)$, lo que explica la acumulación de delitos, ya que en un mismo acto se pueden estar cometiendo dos infracciones penales: la acción delictiva propiamente dicha (amenazas, malos tratos, lesiones, etc.) junto con el quebrantamiento de orden de alejamiento que previamente tenía. En este sentido destaca que el $87,3 \%$ de la muestra estudiada tenía una orden de alejamiento, 
mayoritariamente de la mujer víctima que había sido su pareja, y cuya relación había finalizado (69,5\%). La presencia de otras tipologías delictivas en la muestra estudiada, no relacionadas con la violencia de género, también ofrece una gran diversidad. Sin tener en cuenta los delitos de violencia de género, las infracciones penales más comunes en los participantes son los delitos contra el patrimonio (robos/hurtos, que suponen el $25,2 \%$ ) seguido de los delitos contra la salud pública $(13,6 \%)$, los quebrantamientos de órdenes de alejamiento cuya víctima no es la pareja o expareja $(11,2 \%)$, las lesiones $(9,6 \%)$ y los delitos contra la seguridad del tráfico $(4,8 \%)$.

Todo ello evidencia perfiles criminológicos heterogéneos en los hombres que han participado en el presente estudio y que han cometido delitos de violencia de género, siendo el grupo mayoritario el de hombres con antecedentes penales y penitenciarios que no solo cuentan con delitos de violencia de género en su historial delictivo.

Los resultados del presente estudio ofrecen una aproximación al conocimiento de las características sociodemográficas y penales de los hombres que han sido condenados por delitos de violencia de género en el ámbito de la pareja. Los mismos indican la diversidad presente en los agresores y la dificultad para establecer afirmaciones globales, aunque sí muestran similitudes con otros estudios realizados en cárceles españolas en los últimos años. La ausencia de macroestudios a nivel nacional acerca de la sociodemografía en maltratadores y las características penales y penitenciarias de los mismos hace que el conocimiento de esta población sea intermitente y sesgado, puesto que en algunos estudios no se tiene en cuenta a la población penitenciaria penada por delitos de violencia de género que no forman parte de ningún tratamiento o programa de intervención para agresores, siendo éste el grupo de agresores en la pareja más numeroso dentro de las prisiones espańolas. Pese a todo ello, resulta importante y necesario profundizar en el contexto social y penal de los maltratadores, puesto que ese mayor conocimiento ayudará a entender en mayor profundidad el problema estructural de la violencia de género y a diseñar programas de tratamiento adaptados a la heterogeneidad que muestran los agresores en prisión. 


\section{REFERENCIAS BIBLIOGRÁFICAS}

Arrigoni, Flavia, Jiménez, José Luis, Navarro, José y Mendoza, Pedro. «Aplicación de un programa terapéutico en hombres violentos contra la pareja». Anuario de psicología jurídica, 23 (2013), pp. 3-9.

Barberá, Ester y Mayor, Luis. «Autoconcepto de género y sistema de valores». Revista de Psicologia Social, 2 (1989), pp. 151-165.

Boira Sarto, Santiago. Hombres maltratadores. Historias de violencia masculina. Zaragoza: Prensas Universitarias de Zaragoza, 2010.

Boira Sarto, Santiago y Jodrá, Pedro. «Tipología de hombres condenados por violencia de género en un contexto de intervención psicológica en la comunidad». Revista latinoamericana de Psicología, 2 (2013), pp. 289-303.

Boira Sarto, Santiago, López del Hoyo, Yolanda y Tomás Aragonés, Lucía. «Evaluación cualitativa de un programa de intervención psicológica con hombres violentos dentro de la pareja». Acciones e investigaciones sociales, 28 (2010), pp. 135-156.

Boira Sarto, Santiago, López del Hoyo, Yolanda, Tomás Aragonés, Lucía y Gaspar, Ana. «Intervención psicológica en la comunidad en hombres condenados por violencia de género». Anales de psicología, 1 (2013), pp. 19-28.

Boira Sarto, Santiago y Tomás Aragonés, Lucía. «Características psicológicas y motivación para el cambio en hombres condenados por violencia contra la pareja». International Journal of Psychological Research, 2 (2011), pp. 48-56.

Cabrera Espinosa, Manuel. «Acercándonos al hombre que ejerce la violencia de género: clasificación y descripción de un grupo de maltratadores». Nómadas, Revista crítica de ciencias sociales y jurídicas, 25 (2010), pp. 243-255.

Cantera, Leonor y Blanch, Josep María. «Percepción social de la violencia en la pareja desde los estereotipos de género». Intervención psicosocial, 2 (2010), pp. 121-127.

Caravaca Sánchez, Francisco, García Jarillo, Marina, Sánchez-Alcaraz Martínez, C. y Luna Maldonado, Aurelio. "Estudio del consumo de sustancias psicoactivas y conflictividad familiar en sujetos condenados por delitos de violencia de género». Cuadernos de medicina forense, 20 (2014), pp. 92-98.

Casique Casique, Leticia y Ferreira Furegato, Antonia Regina. «Violencia contra mujeres: reflexiones teóricas». Revista latinoamericana Enfermagem, 14 (2006), pp. 950-958.

Cervelló Donderis, Vicenta. Derecho Penitenciario. Valencia: Tirant Lo Blanch, 2012.

Chérrez Bermejo, C. y Alás Brun, R. «A descriptive study of sustance abuse and mental health disorders in intimate partner violence abusers in prison». Revista especial de sanidad penitenciaria, 16 (2014), pp. 29-37.

Colás Bravo, Pilar y Villaciervos Moreno, Patricia. «La interiorización de loes estereotipos de género en jóvenes y adolescentes». Revista de investigación educativa, 1 (2007), pp. 35-58.

Contreras Taibo, Lorena. «Factores de riesgo de homicidio de la mujer en la relación de pareja». Universitas Psychologica, 13 (2014), pp. 681-692.

Cruz Márquez, Beatriz y Martín Ríos, Blanca. «Factores influyentes en la percepción de la responsabilidad por parte del agresor de género en prisión». Boletín criminológico del Instituto Andaluz interuniversitario de Criminología, 160 (2015), pp. 1-6. 
De Alencar-Rodrigues, Roberta y Cantera, Leonor. «Violencia de género en la pareja: una revisión teórica». Psico, 1 (2012), pp. 116-126.

Delgado-Álvarez, María Carmen, Sánchez Gómez, María Cruz y Fernández-Dávila Jara, Paula Andrea. "Atributos y estereotipos de género asociados al ciclo de la violencia contra la mujer». Universitas Psychologica, 3 (2012), pp. 769-777.

De los Galanes, María José y Tabernero, Carmen. «El impacto del entrenamiento cognitivo-conductual. Un estudio exploratorio con agresores de género». Anuario de psicología jurídica, 23 (2013), pp. 11-19.

De Miguel Álvarez, Ana. «La construcción de un marco feminista de interpretación: la violencia de género». Cuadernos de trabajo social, 18 (2005), pp. 231-248.

Duarte, Efraín, Gómez, Jorge Francisco y Carrillo, Carlos David. «Masculinidad y hombre maltratador ¿pueden las creencias de hombres y mujeres propiciar violencia de género?». Revista de psicología, 2 (2010), pp. 7-30.

DutTon, Donald. «Profiling of wife assaulters: preliminary evidence for a trimodal analysis». Violence and victims, 1 (1988), pp. 5-29.

Echauri Tijeras, José Antonio, Fernández-Montalvo, Javier, Martínez Sarasa, María y Azcárate Seminario, Juana María. «Trastornos de personalidad en hombres maltratadores a la pareja: perfil diferencial entre agresores en prisión y agresores con suspensión de condena». Anuario de psicología jurídica, 21 (2011), pp. 97-105.

Echeburúa Odriozola, Enrique, Fernández-Montalvo, Javier y Amor, Pedro. «Psychopatological profile of men convicted of gender violence. A study in the prisons of Spain». Journal of interpersonal violence, 10 (2003), pp. 1-15.

Echeburúa Odriozola, Enrique, Fernández-Montalvo, Javier y De Corral, Paz. «¿Hay diferencias entre la violencia grave y la violencia menos grave contra la pareja?: un análisis comparativo». International journal of clinical and health psychology, 2 (2008), pp. 355-382.

Echeburúa Odriozola, Enrique, Fernández-Montalvo, Javier y De la Cuesta, José Luis. «Articulación de medidas penales y de tratamiento psicológico en los hombres violentos en el hogar». Psicopatología clínica, 2 (2001), pp. 19-31.

European Union Agency For Fundamental Rights. Violence against women: an EU wide survey, 2014 (http://fra.europa.eu/en/publication/2014/violence-against-women-eu-wide-survey-main-results-report).

Expósito, Francisca. «Violencia de género». Mente y cerebro, 48 (2011), pp. 20-25.

Fernández Romero, Diana. «La incidencia de las campañas institucionales sobre violencia de género en el proceso identitario de mujeres maltratadas». Asparkía, 24 (2013), pp. 126-143.

Fernández Romero, Enrique, Espino Pérez, Rafael, Aguilera Peña, Manuel, Pablo Vázquez, María Dolores, Galán Doval, Carlos Javier y Recio Ramírez, José Manuel. «Violencia doméstica atendida en urgencias de un hospital comarcal: características sociodemográficas de víctima y agresor». Emergencias, 20 (2008), pp. 164-172.

Fernández-Montalvo, Javier, Echauri, José, Martínez, María y Azcárate, Juana María. «Violencia de género e inmigración: perfil diferencial de hombres maltratadores nacionales e inmigrantes». Behavioral Psychology, 2 (2011), pp. 439-452.

Fernández-Montalvo, Javier y Echeburúa Odriozola, Enrique. «Trastornos de personalidad y psicopatía en hombres condenados por violencia grave contra la pareja». Psicothema, 2 (2008), pp. 193-198. 
Fernández-Montalvo, Javier y Echeburúa Odriozola, Enrique. «Variables psicopatológicas y distorsiones cognitivas de los maltratadores en el hogar: un análisis descriptivo». Análisis y modificación de conducta, 88 (1997), pp. 151-180.

Fernández-Montalvo, Javier, Echeburúa Odriozola, Enrique. y Amor, Pedro José. "Aggressors against women in prison and in the community: an exploratory study of a differential profile». International Journal of offender therapy and comparative criminology, 49 (2005), pp. 158-167.

Ferrer Pérez, Victoria y Bosch Fiol, Esperanza. "Gender violence as a social problem in Spain: attitudes and acceptability». Sex roles, 70 (2014), pp. 506-521.

Ferrer Pérez, Victoria y Bosch Fiol, Esperanza. «Violencia de género y misoginia: reflexiones psicosociales sobre un posible factor explicativo». Papeles del psicólogo, 75 (2000), pp. 13-19.

Ferrer Pérez, Victoria, Bosch Fiol, Esperanza, Ramis Palmer, María del Carmen y Navarro Guzmán, Capilla. "Las creencias y actitudes sobre la violencia contra las mujeres en la pareja: determinantes sociodemográficos, familiares y formativos». Anales de psicología, 22 (2006), pp. 251-259.

Gottman, John, Jacobson, Neil, Rushe, Regina, Shortt, Joan Wu, Babcock, Julia, La TaiLLADE, Jaslean y WALTZ, Jennifer. «The relationship between heart rate reactivity, emotionally aggressive behavior and general violence in batterers». Journal of family Psychology, 9 (1995), pp. 227-248.

Holtzworth-Munroe, Amy, Bates, Leornard, Smutzler, Natalie y Sandin, Elizabeth. «A brief review of the research on husband violence». Aggression and violent behavior, 1 (1997), pp. 65-99.

Holtzworth-Munroe, Amy y Stuart, Gregory. «Typologies of male batterers: three subtypes and the differences among them». Psychological Bulletin, 3 (1994), pp. 476-497.

Ley Orgánica 1/1979, de 26 de septiembre, General Penitenciaria (https://www.boe.es/buscar/ pdf/1979/BOE-A-1979-23708-consolidado.pdf).

Ley Orgánica 10/1995, de 23 de noviembre, del Código Penal (https://www.boe.es/buscar/pdf/1995/ BOE-A-1995-25444-consolidado.pdf).

Ley Orgánica 1/2004, de 28 de diciembre, de medidas de protección integral contra la violencia de género (https://www.boe.es/buscar/pdf/2004/BOE-A-2004-21760-consolidado.pdf).

Loinaz, Ismael, Echeburúa, Enrique y Torrubia, Rafael. «Tipología de agresores contra la pareja en prisión». Psicothema, 1 (2010), pp. 106-111.

Lorente, Miguel. «El maltratador, la condición masculina y el maltrato a las mujeres». Crítica, 960 (2009), pp. 44-47.

Martín SÁnchez, María. «El género en la violencia afectiva: clave para un examen de constitucionalidad». Estudios constitucionales, 1 (2015), pp. 203-236.

Matud Aznar, María Pilar, Carballeira Abella, Mónica, Marrero Quevedo, Rosario, Aguilera Ávila, Laura, Moraza Pulla, Olga y Pérez Trujlllo, Nieves. "Características sociodemográficas y conductuales de los agresores a su pareja». Psicopatología clínica, legal y forense, 2 (2002), pp. 5-22.

Ministerio de Sanidad, Servicios Sociales e Igualdad, 2015, Macro encuesta de violencia contra la mujer 2015: avance de resultados (http://www.msssi.gob.es/ssi/violenciaGenero/publicaciones/estudiosinvestigaciones/PDFS/AVANCE_MACROENCUESTA_DE_VIOLENCIA_CONTRA_LA_MUJER_2015.pdf). 
Ministerio del Interior. Fondo documental de la Secretaría General de Instituciones Penitenciarias, 2019, (http://www.institucionpenitenciaria.es/web/portal/documentos).

Organización Mundial de la SAlud (OMS). Informe mundial sobre la violencia y la salud. Washington: Organización Panamericana de la Salud, 2003.

Peixoto Caldas, José Manuel y Mauricio Gessolo, Kleber. «Violencia de género: nuevas realidades y nuevos retos». Saude Social Sao Paulo, 3 (2008), pp. 161-170.

Pelegrín Muñoz, Antonia y Garcés de los Fayos Ruiz, Enrique. «Aproximación teórico-descriptiva de la violencia de género: propuestas para la prevención». Apuntes de psicología, 3 (2004), pp. 353-373.

Pérez Ramírez, Meritxell, Giménez-Salinas Framís, Andrea y De Juan Espinosa, Manuel. «Evaluación de la eficacia del programa de tratamiento con agresores de pareja (PRIA) en la comunidad». PsYchosocial Intervention, 22 (2013), pp. 105-114.

Sordi STOCK, Bárbara. «Programas de rehabilitación para agresores en España: un elemento indispensable de las políticas de combate a la violencia de género». Política criminal, 19 (2015), pp. 297-317.

Subirana Malaret, Montse y Andrés Pueyo, Antonio. «Retención proactiva y adherencia terapeútica en programas formativos para hombres maltratadores de la pareja». Psychosocial intervention, 22 (2013), pp. 95-104.

VARgas, Viviana, Lila, Marisol y Catalá-Miñana, Alba. «infnfluyen las diferencias culturales en los resultados de los programas de intervención con maltratadores? Un estudio con agresores españoles y latinoamericanos». Psychosocial intervention, 24 (2015), pp. 41-47.

Vives Cases, Carmen, Álvarez Dardet, Carlos, Carrasco Portiño, Mercedes y Torrubiano Domínguez, Jordi. «El impacto de la desigualdad de género en la violencia del compañero íntimo en España». Gaceta sanitaria, 3 (2007), pp. 242-246.

Vives Cases, Carmen, Gil González, Diana, Carrasco Portiño, Mercedes y Álvarez Dardet, Carlos. «Revisión sistemática de los estudios sobre el nivel socioeconómico de los hombres que maltratan a sus parejas». Gaceta sanitaria, 5 (2007), pp. 425-430.

World Health Organization. «Global and regional estimates of violence against women: prevalence and health effects of intimate partner violence and non-partner sexual violence», 2013 (http://www.who.int/reproductivehealth/publications/violence/9789241564625/en/). 
